\title{
Rancang Bangun Sistem Kontrol Lampu Berbasis Arduino Mega 2560
}

\author{
Anathasya Virginia ${ }^{1}$, Prio Handoko ${ }^{2}$, Hendi Hermawan ${ }^{3}$ \\ ${ }^{1}$ Progam Studi Informatika Universitas Pembangunan Jaya, \\ anathasya.virginia@student.upj.ac.id \\ ${ }^{2}$ Program Studi Informatika, Universitas Pembangunan Jaya, \\ prio.handoko@upj.ac.id \\ ${ }^{3}$ Program Studi Informatika, Universitas Pembangunan Jaya, \\ hendi.hermawan@upj.ac.id
}

\begin{abstract}
Lamp controlling system at Pembangunan Jaya University is currently still done manually, and some of the lamps are supported by timer. There are 9 floor at Pembangunan Jaya University, and imagine every night security has to go around each floor to make sure that every lamp in every rooms have turned off? And when there's a broken lamp, Bagian Umum won't able to fix the lamp soon. By this case, this research aims to build a lamp controlling system which can be accessed by web that developed using HTML. Also, this lamp controlling system can detect the condition of the lamp in the room so when there's a broken lamp, it can be monitored by the security and Bagian Umum to be soon fixed. There are main components to do this research; Arduino Mega 2560, Arduino Ethernet Shield as a connection between the hardware to the internet, motion sensor/PIR as a detector if there's a movement in the room, light sensor/LDR as light resistant receiver on lamp to help monitoring on the lamp condition, this research also uses Prototype method. The output of this research is to build lamp controlling system which can help security and Bagian Umum to monitor the lamp easier, and to provide comforts to the room user.
\end{abstract}

Keywords : Lamp Controlling System, Microcontroller, Arduino Mega 2560, HTML, Prototype

\begin{abstract}
Abstrak : Sistem kontrol lampu di Universitas Pembangunan Jaya saat ini masih dilakukan secara manual dengan beberapa lampu yang dibantu dengan timer. Padahal gedung Universitas Pembangunan Jaya ini memiliki 9 lantai, dapat dibayangkan Satpam tiap malamnya harus memastikan kondisi lampu ruangan semua dalam kondisi mati? Belum lagi ketika terjadi kerusakan pada lampu di ruangan, Bagian Umum tidak dapat langsung memperbaiki lampu yang rusak tersebut. Oleh karena itu, penelitian ini bertujuan untuk membangun sistem kontrol lampu dimana sistem kontrol lampu ini dapat diakses melalui web yang dirancang menggunakan HTML. Terdapat komponen utama yang digunakan pada penelitian ini yaitu Arduino Mega 2560, Arduino Ethernet Shield sebagai penghubung perangkat keras ke internet, sensor gerak/PIR sebagai pendeteksi ada atau tidaknya gerakan pada ruangan, dan sensor cahaya/LDR sebagai penerima resistensi cahaya pada lampu ruang guna membantu pengecekkan pada kondisi lampu, serta metode yang digunakan pada penelitian ini adalah metode prototype. Hasil akhir yang didapatkan adalah sistem kontrol lampu ini dapat membantu memudahkan pekerjaan Bagian Umum dan Satpam, dan dapat memberikan kenyamanan pada pengguna ruangan.
\end{abstract}

Kata Kunci : Sistem Kontrol Lampu, Mikrokontroler, Arduino Mega 2560, HTML, Prototipe 


\section{PENDAHULUAN}

Di era ini perkembangan teknologi pun kian pesat hingga pengembangan ilmu teknologi dikembangkan menjadi suatu yang dapat mempermudah manusia dalam kegiatan sehari-hari. Dengan maraknya pengembangan teknologi dalam bidang otomasi dan sistem kontrol ini, sangat memudahkan kegiatan/aktifitas manusia sehari-hari, terlebih dalam penggunaan lampu. Sejak ditemukannya lampu pijar oleh Alessandro Volta pada tahun 1802 yang kemudian Thomas Alva Edison menemukan Bola lampu (lampu bohlam) pada tahun 1879, sehingga lampu merupakan kebutuhan primer untuk saat ini. Penggunaan lampu berguna untuk sektor industri, pendidikan, rumah tangga, mau pun penerangan untuk jalanan. Sehingga tidak dapat dipungkiri bahwa eksistensi lampu merupakan hal yang bermanfaat untuk manusia hingga saat ini.

Sektor pendidikan, seperti Universitas Pembangunan Jaya (UPJ) pun jelas menggunakan lampu di setiap ruangan di masing-masing lantainya. Namun, belum ada sistem kontrol yang terhubung pada lampu-lampu yang digunakan di Universitas Pembangunan Jaya (UPJ). Sehingga Satpam UPJ pun harus melakukan pemeriksaan ke masing-masing lantai setiap harinya untuk memeriksa apa kah lampu pada ruangan sudah mati atau belum. Selain itu, jika terjadi kerusakan pada lampu, Bagian Umum dan Satpam UPJ tidak langsung dapat mengetahuinya untuk ditindaklanjuti. Pengguna ruangan masih harus memberi informasi kerusakan lampu pada ruangan ke Bagian Umum, belum lagi jika ada pengguna ruangan yang tidak peduli dengan kondisi lampu yang rusak sehingga pengguna lampu tersebut tidak langsung memberi tahu Bagian Umum atau Satpam UPJ terkait kerusakan lampu pada suatu ruangan. Hal ini merupakan isu yang kurang dilihat oleh banyak masyarakat Universitas Pembangunan Jaya, namun jika sistem manual seperti ini dibenahi dan dikembangkan menggunakan teknologi, akan sangat memudahkan Bagian Umum dan Satpam dalam pemantauan kondisi lampu di masing-masing ruangan, serta dapat memberikan kenyamanan kepada pengguna ruang terkait dengan kondisi lampu yang baik.

\section{Permasalahan}

Permasalahan yang dirumuskan pada penelitian ini adalah bagaimana menciptakan suatu inovasi dengan ilmu teknologi informatika yang dapat memudahkan pemantauan penggunaan dan kondisi lampu di masing-masing ruangan di Universitas Pembangunan Jaya.

\section{Tujuan Penelitian}

Penelitian ini memiliki tujuan seperti mempermudah pekerjaan Satpam dan Bagian Umum di Universitas Pembangunan Jaya dalam pemantauan penggunaan dan kondisi ruangan di Universitas Pembangunan Jaya, serta memberikan kenyamanan kepada pengguna lampu di Universitas Pembangunan Jaya dalam menggunakan ruangan.

\section{KAJIAN PUSTAKA Sistem Kontrol}

Sistem kontrol atau sistem kendali merupakan suatu sistem dimana masukkan tertentu dapat digunakan sebagai pengendali untuk luaran dengan nilai tertentu, mengurutkan suatu proses atau membuat suatu luaran jika beberapa kondisi terpenuhi. (Eddi Kurniawan, 2013)

\section{Mikrokontroler}

Mikrokontroler merupakan sebuah sistem komputer fungsional dalam sebuah chip. Di dalamnya terkandung sebuah inti prosesor, memori (sejumlah kecil RAM, memori program, atau keduanya), dan perlengkapan input/output. Mikrokontroler adalah salah satu dari bagian dasar dari suatu sistem komputer. Meskipun mempunyai bentuk fisik yang lebih kecil dari suatu komputer pribadi dan komputer mainframe, mikrokontroler dibangun dari 
elemen-elemen dasar yang sama. Secara sederhana, komputer akan menghasilkan output spesifik berdasarkan input yang diterima dan program yang dikerjakan. (Muhammad Syahwil, 2013)

\section{Metode Prototipe}

Model prototipe adalah sebuah versi dari suatu sistem potensial yang menyediakan pengembang dan user dengan suatu gambaran tentang bagaimana sistem dalam bentuk sempurnanya akan berfungsi. proses untuk menghasilkan sebuah prototipe disebut prototyping. Tahapan-tahapan dalam pengembangan prototipe, antara lain; tahapan identifikasi kebutuhan pemakai, tahap perancangan desain, tahap perancangan sistem/alat, tahap pengujian, dan tahap penggunaan. (Seno Aji Hasmoro, 2014)

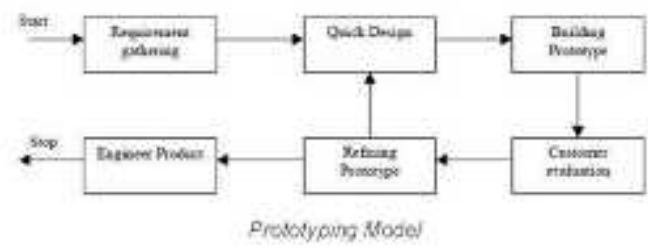

Gambar 1. Model Prototype

\section{METODE PENELITIAN}

Penelitian ini menggunakan metode penelitian prototipe dimana terdapat enam tahapan.

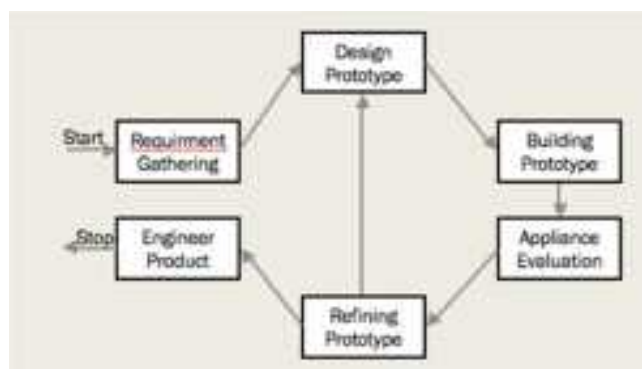

Gambar 2. Bagan Metode Prototipe

Tahap awal yaitu Requirement gathering di mana dilakukan pengumpulan data dan informasi berdasarkan dengan kebutuhan dalam pengembangan sistem. Data dan informasi yang terkumpul akan dianalisis dan dikembangkan. Hasil yang didapatkan dari tahap pengumpulan data dan informasi akan diimplementasikan pada desain terhadap pengembangan sistem yang akan dirancang pada tahap Quick Design dan akan disesuaikan dengan kebutuhan user. Selanjutnya akan dilakukan tahap Building prototype yaitu membangun prototype sesuai dengan desain dan kebutuhan yang sudah dirancang sedemikian rupa pada tahap sebelumnya. Tahap selanjutnya adalah Customer evaluation di mana akan dilakukan pengujian prototype sistem yang telah dibangun pada tahap sebelumnya yang kemudian akan saring pada tahap Refining prototype yang akan mengeluarkan suatu hasil apakah prototype yang dibangun sudah sesuai atau belum dengan kebutuhan user. Jika dalam pengujian sistem ini gagal maka akan kembali lagi ketahap quick design, dari hasil pengujian di tahap sebelumnya pula akan disaring untuk dilakukan perubahan di tahap quick design. Terakhir, setelah uji saring selesai akan lanjut ke tahap Engineer product merupakan tahap pengujian sudah sesuai dengan kebutuhan sistem dan user maka produk tersebut sudah layak untuk digunakan.

\section{ANALISIS DAN PERANCANGAN Analisis Sistem Berjalan}

Universitas Pembangunan Jaya memiliki satu gedung, dengan sembilan lantai. Pada lantai dasar, terdiri dari beberapa kelas, ruang BP, dan ruang Satpam. Pada lantai 2, terdiri dari kantin dan ruang marketing. Pada lantai 3, terdapat beberapa kelas dan aula. Pada lantai 4, terdapat perpustakaan dan ruangan staff. Pada lantai 5, terdiri dari ruang dosen dan beberapa lab. Pada lantai 6 dan 7, terdiri dari ruangan kelas. Pada lantai 8 merupakan lantai yang digunakan oleh Yayasan Pembangunan Jaya. Dan yang terakhir lantai 9 adalah lapangan futsal dan basket. Sistem kontrol lampu di Universitas Pembangunan Jaya dikontrol oleh Bagian Umum dan diberikan kepercayaan ke Satpam untuk mengawasi kondisi lampu di masing-masing lantai 
terkecuali untuk lantai 8, karena pada lantai 8 digunakan oleh Yayasan Pembangunan Jaya. Jadwal sistem kontrol lampu pada Universitas Pembangunan Jaya untuk lampu kooridor dan kantin telah diberikan timer akan menyala setiap pukul 6:00 sore sampai dengan 10:00 malam dan setiap pukul 4:30 pagi sampai dengan 7:00 pagi.

Lain halnya dengan lampu kelas, pada ruang kelas akan dinyalakan sesuai dengan penggunaan kelas oleh dosen dan mahasiswa namun pada umumnya sama seperti ruang dosen, lantai 4 dan marketing akan dinyalakan pada pukul 6:00 pagi sampai dengan pukul 10:00 malam biasanya, dan maksimal untuk ruangan tersebut akan menyala sampai pukul 12:00 malam sesuai dengan kebutuhan pengguna terkait. Pada lantai 9 hanya ada lampu pada kooridor lift dan lampu kooridor hanya menyala ketika lantai 9 akan digunakan. Selain itu, Bagian Umum melakukan perbaikan lampu setiap satu semester sekali, ketika pergantian semester (6 bulan sekali). Namun tidak menutup kemungkinan penggantian lampu dilakukan saat masa-masa perkuliahan ketika Bagian Umum menerima laporan lampu rusak pada ruangan. [Tjantoko, Hasil Wawancara, 22 Juni 2018]

Berdasarkan hasil wawancara yang dilakukan dengan Pak Tjantoko bahwa saat ini di Universitas Pembangunan Jaya sistem kontrol lampu masih dilakukan secara manual. Satpam masih harus keliling naik ke tiap lantai untuk memastikan bahwa lampu di masingmasing kelas dalam kondisi mati pada jamjam tertentu lampu sudah harus dalam kondisi mati. Selain itu, ketika terjadi kerusakan pada suatu lampu di ruangandi luar masa perbaikan lampu, Bagian Umum tidak dapat langsung mengetahui dan memperbaikinya. Pengguna kelas harus memberi laporan terlebih dahulu ke Bagian Umum dan membuat laporan melalui formulir kerusakan ketika terjadi kerusakan lampu, belum lagi jika pengguna ruangan acuh terhadap kondisi lampu pada ruangan. Jelas hal seperti ini menjadi kurang efisien dan melelahkan bagi beberapa unit.

\section{PERANCANGAN SISTEM Desain Alat dan Interface}

Sebelum melakukan tahap perancangan/perangkaian alat, dilakukan perancangan desain alat. Berikut merupakan gambaran rancangan desain yang telah dibuat. Kotak A dan B merupakan akrilik, A merupakan simulator ruang/kelas dengan alas berwarna hitam, dan B merupakan case untuk papan sirkuit Arduino yang dapat dibuka bagian atasnya, serta terdapat lubang untuk akses kabel jumpet keluar ke lampu, sensor PIR, dan sensor LDR. Dua kotak biru yang bersebelahan merupakan rumah lampu yang berisi lampu dan sensor LDR, dan lingkaran hitam merupakan sensor PIR. Ukuran kotak A adalah $32 \times 23 \times 10 \mathrm{~cm}$ sedangkan untuk kotak $B$ berukuran 7x12x10 cm. Dapat dilihat pada Gambar 3 . Serta pada Gambar 4 menunjukkan laman web yang akan dirancang.

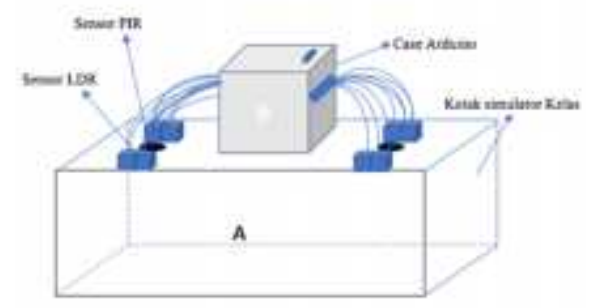

Gambar 3. Desain Alat

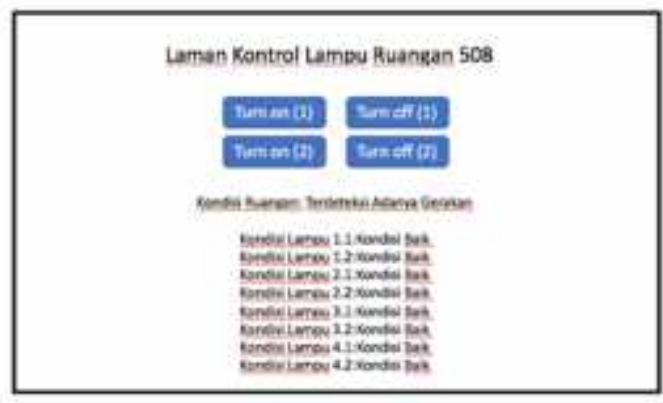

Gambar 4. Rancangan Interface

\section{Flowchart}

Pada penelitian ini telah dirancang flowchart untuk menentukan cara kerja dari sistem kontrol lampu. Flowchart ini 
dirancang untuk mempermudah perancangan sistem kontrol lampu. Flowchart yang dirancang pada sistem kontrol ini dibagi menjadi tiga flowchart yaitu, Flowchart Keseluruhan Sistem Kontrol Lampu yang terlampir pada Gambar 5, Flowchart Status Ruangan yang terlampir pada Gambar 6, dan Flowchart Status Lampu yang terlampir pada Gambar 7. Penjabaran flowchart keseluruhan akan dilampirkan pada halaman lampiran.
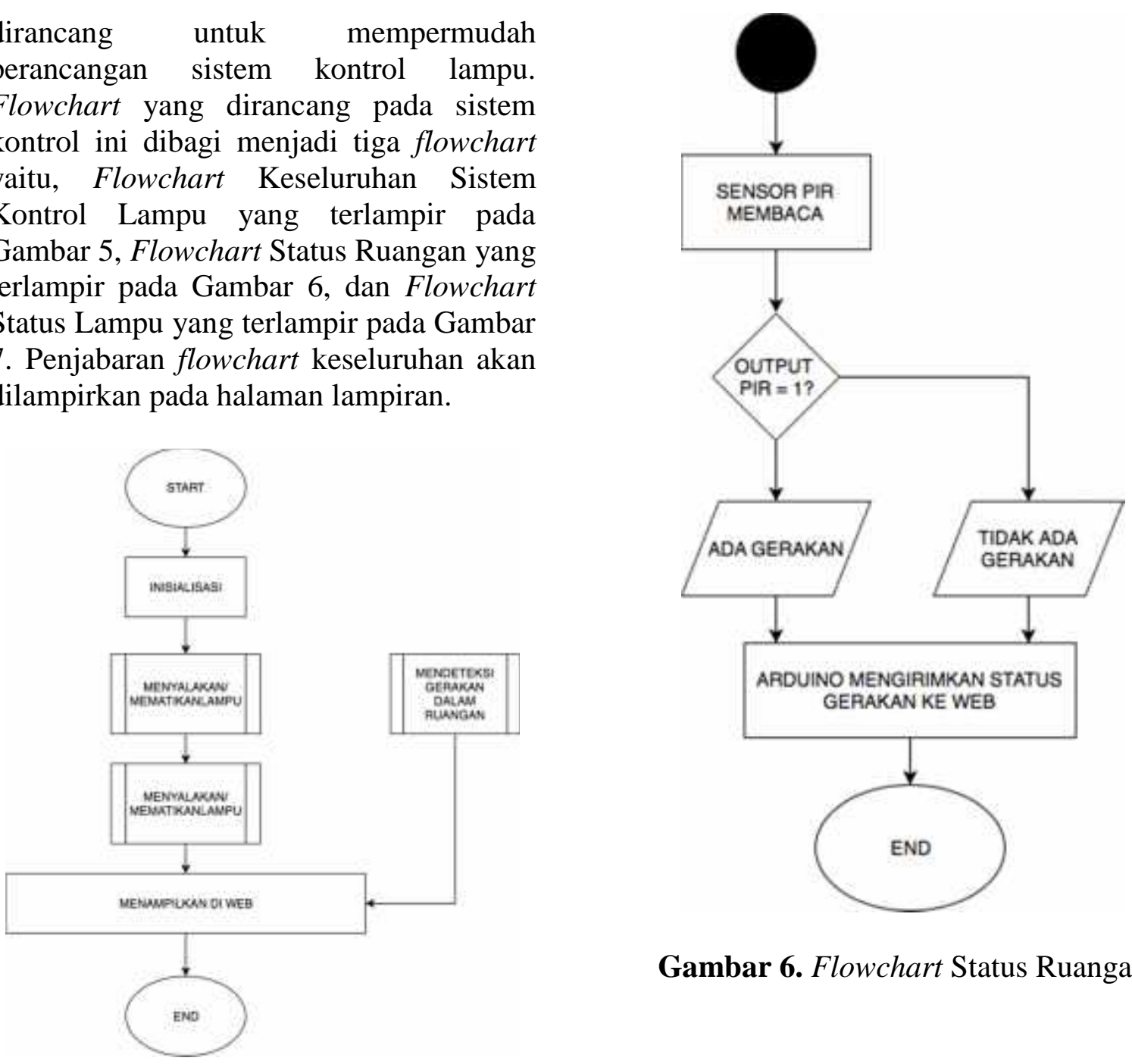

Gambar 6. Flowchart Status Ruangan

Gambar 5. Flowchart Keseluruhan

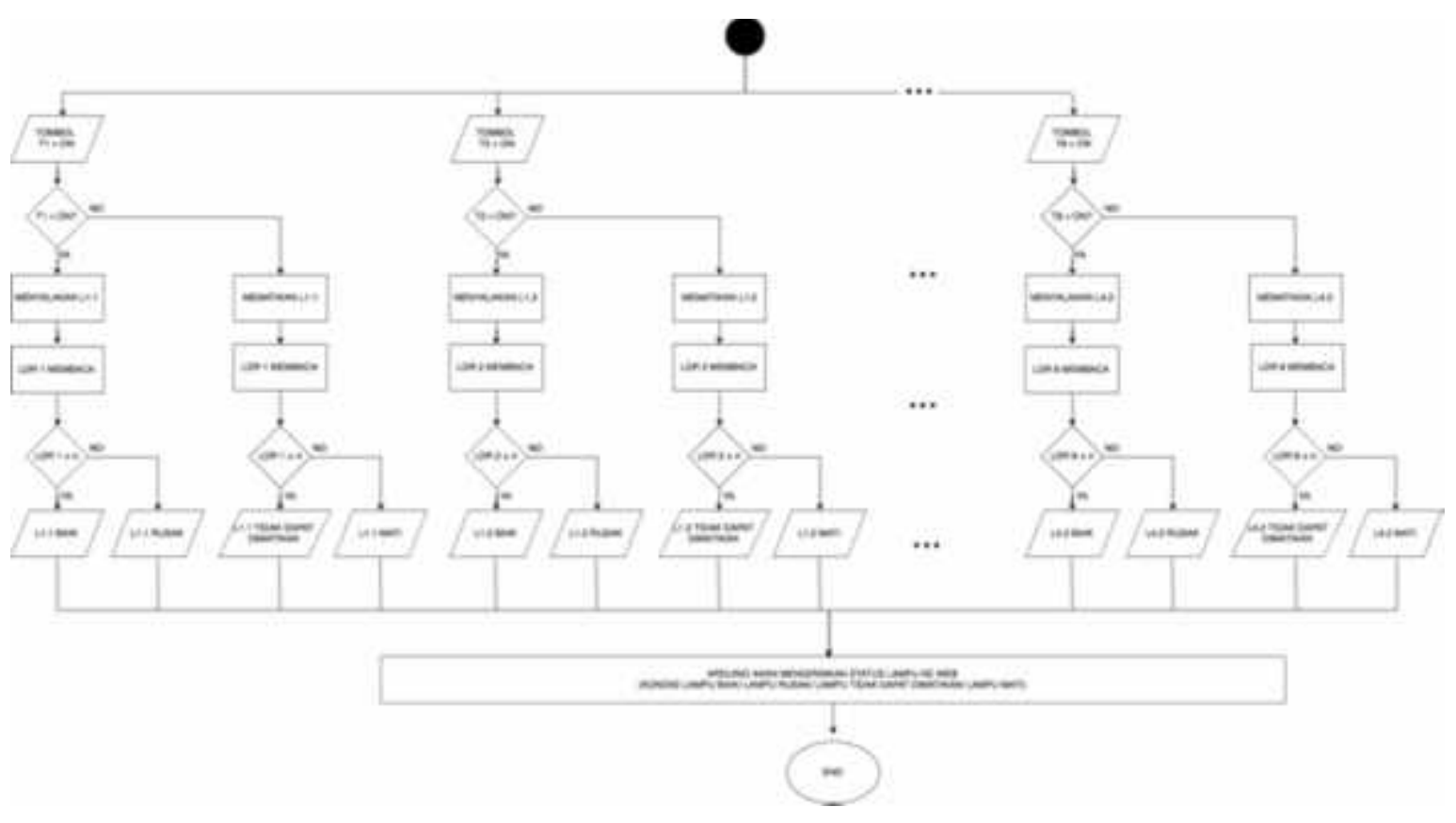


Gambar 7. Flowchart Status Lampu

terdeteksi adanya gerakan pada ruangan. Hasil output dari sensor PIR ini akan ditampilkan pada halaman web. Sensor LDR akan membaca berdasarkan intensitas cahaya lampu pada ruangan, dengan memberikan output 1 sebagai intensitas cahaya terang dan output 0 sebagai intensitas cahaya redup/gelap. Hasil dari pembacaan sensor LDR ini pula akan dikirimkan ke web untuk ditampilkan. Selain itu, terdiri dari dua tombol Turn On dan dua tombol Turn Off untuk menyala dan mematikan lampu pada ruangan. Terdapat delapan lampu yang akan dibagi menjadi empat grup lampu dimana masing-masing grup lampu terdapat dua bohlam lampu yang akan disimulasikan menggunakan LED, yang kemudian akan dibagi lagi menjadi dua saklar yang terdiri akan dua grup lampu pada masing-masing saklar.

\section{HASIL DAN PEMBAHASAN Gambaran Umum Objek Penelitian}

Objek penelitian kali ini merupakan sistem kontrol yang menggunakan perangkat keras dan lunak, dan bagaimana cara agar perangkat keras dan perangkat lunak itu dapat saling terhubung satu sama lain menjadi suatu sistem kontrol lampu di Universitas Pembangunan Jaya. Sistem kontrol lampu ini dibangun menggunakan Arduino Mega 2560 sebagai pengatur dan kontroler dari keseluruhan perangkat sistem kontrol lampu, sensor gerak/PIR yang digunakan untuk pendeteksi adanya gerak atau tidak pada ruangan, sensor cahaya/LDR yang digunakan sebagai pendeteksi rusak atau tidaknya lampu pada ruangan. Perangkat lunak pun dibutuhkan sebagai pendukung dalam sistem kontrol lampu ini dimana sebuah halaman web HTML digunakan sebagai suatu antar muka halaman sistem kontrol untuk digunakan oleh pengguna.

Sensor PIR akan diprogram untuk mendeteksi adanya gerakan pada suatu ruangan, sehingga sensor PIR akan memberikan output 1 jika terdeteksi adanya gerakan dan output 0 jika tidak

\section{Gambaran Umum Subjek Penelitian}

Pengguna sistem kontrol lampu yang dirancang bangun pada penelitian ini adalah Satpam dan Bagian Umum sebagai end user. Sistem kontrol lampu ini disajikan dengan sebuah interface dengan dua tombol yaitu tombol untuk menyala dan mematikan lampu. Selain itu, terdapat informasi mengenai kondisi ruangan yang berasal dari input sensor PIR dan kondisi lampu pada ruangan yang berasal dari input sensor LDR. Interface yang dibangun berupa web yang dapat dibuka pada web browser hanya dengan memasukkan URL 192.168.0.99, dan jaringan terhubung dengan router dengan default gateway yang sudah diprogram.

\section{Tahapan Perakitan Alat}

Gambar 8 merupakan tahap memrogram sensor gerak PIR. Dimulai dari memprogram satu sensor gerak PIR saja, yang kemudian menggabungkan dua sensor gerak PIR menjadi satu program. Diberikan LED merah sebagai indikator 
ketika sensor gerak PIR tersebut mendeteksi adanya gerakan.

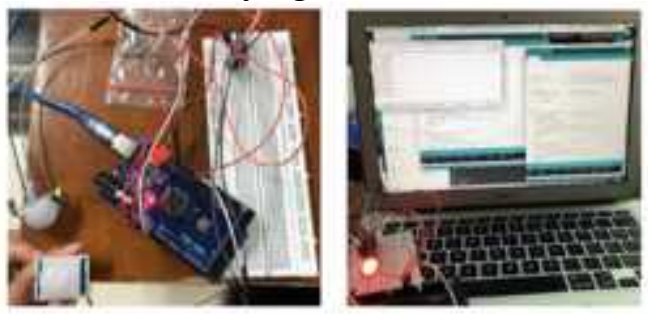

Gambar 9. Perakitan dan Pemrograman Sensor PIR

Gambar 9 menunjukkan saat pembuatan dan perakitan rumah lampu dan sensor cahaya LDR. Dibuat menggunakan cardboard yang dibentuk persegi dan dilapisi alumunium foil pada bagian sisi dalamnya bertujuan agar cahaya dapat terpantul secara sempurna, sehingga sensor cahaya LDR dapat mendeteksi cahaya dari LED dengan baik.
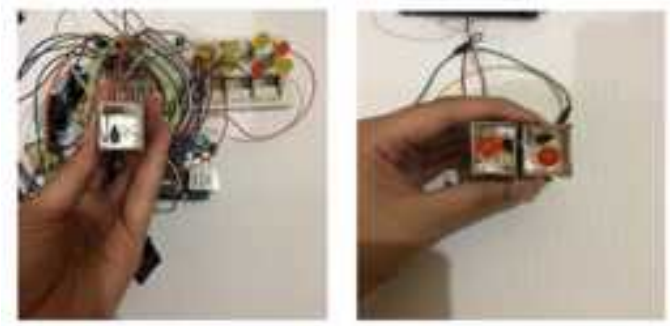

Gambar 10. Pembuatan Rumah Lampu dan Sensor LDR

Selanjutnya adalah tahap perakitan simulasi ruangan dan case untuk Arduino seperti pada Gambar 10. Simulasi ruangan dan case ini dibuat menggunakan akrilik.
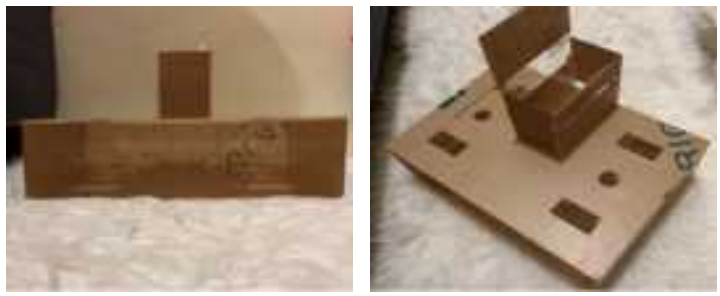

Gambar 11. Simulasi Ruangan dan Case Arduino

\section{Pengujian Alat/Sistem}

Pada tahap ini dilakukan pengujian alat dan sistem. Berikut merupakan pengujian yang dilakukan.

Tabel 1. Tabel Pengujian LDR

\begin{tabular}{l|c|c|}
\hline No. & Intensitas Cahaya & Ket \\
\hline 1 & 170 & TS \\
\hline 2 & 180 & TS \\
\hline 3 & 190 & TS \\
\hline 4 & 200 & SS \\
\hline \\
*TS = Tidak Sesuai \\
*SS = Sudah Sesuai
\end{tabular}

Pada Tabel 1, menjelaskan mengenai hasil pengujian intensitas cahaya yang cocok untuk sensor LDR. Dilakukan pengujian pada pemrograman pada sensor LDR, dimana intensitas yang digunakan pada pengujian pertama adalah pada angka 170.

Pada intensitas 170, sensor LDR belum membaca intensitas cahaya terang pada kondisi lapangan, sehingga perlu dinaikkan ke pengujian kedua dimana intensitas cahaya yang digunakan pada program adalah 180. Sama seperti pengujian awal, dimana pada intensitas 180 ini masih belum dapat membaca intensitas cahaya terang pada ruangan pada kondisi lapangan. Pengujian ketiga dilakukan dengan mengganti intensitas cahaya pada angka 190, namun pada intensitas cahaya 190 ini masih dianggap kurang cocok karena pada beberapa kondisi, sensor LDR ini tidak dapat mendeteksi cahaya pada ruangan. Sehingga angka untuk pengujian sensor LDR ini perlu dinaikkan pada angka 200. Pada intensitas 200 ini, sensor LDR dapat mendeteksi intensitas cahaya ruangan dengan baik, maka angka 200 ini akan digunakan pada pemrograman sensor LDR dalam pendeteksian intensitas cahaya gelap atau terangnya pada ruangan.

Pada tabel 2 dapat dilihat pada nomor 1 sampai dengan 3 merupakan hasil pengujian sensor PIR, pada nomor 4 dan 5 merupakan hasil pengujian sensor LDR, dan yang terakhir pada nomor 6 merupakan hasil pengujian tombol turn on dan off pada interface.

Tabel 2. Pengujian Black Box 


\begin{tabular}{|c|c|c|c|c|}
\hline N:. & 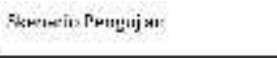 & $\begin{array}{l}\text { How vat } \\
\text { Wharveks }\end{array}$ & $\begin{array}{l}\text { Heii } \\
\text { Pengomstan }\end{array}$ & KNol. \\
\hline 1 & 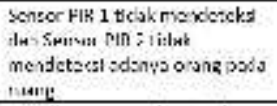 & $\begin{array}{l}\text { Indikstor LLD } \\
\text { lusik } \\
\text { meryals }\end{array}$ & 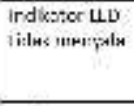 & $v$ \\
\hline 2 & 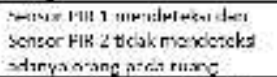 & $\begin{array}{l}\text { Imikgian itis } \\
\text { meryals }\end{array}$ & $\begin{array}{l}\text { Irdikniex It } \\
\text { meryals }\end{array}$ & 8 \\
\hline 3 & 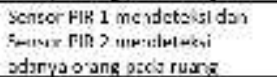 & $\begin{array}{l}\text { Indikstor LLD } \\
\text { minivate }\end{array}$ & 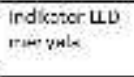 & $v$ \\
\hline 4 & $\begin{array}{l}\text { Sentor LJK I de asen L.U } \\
\text { menivla }\end{array}$ & $\begin{array}{l}\text { Poovomptkan } \\
\text { cutput } 1 \\
\text { padasatol } \\
\text { iachitar }\end{array}$ & 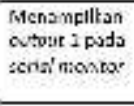 & $\mathrm{v}$ \\
\hline 3 & 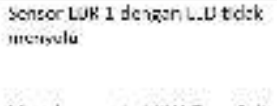 & 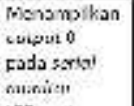 & $\begin{array}{l}\text { Acns mpilltan } \\
\text { cutout Opadu } \\
\text { ecris' niontar }\end{array}$ & $v$ \\
\hline 5 & 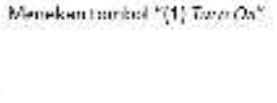 & 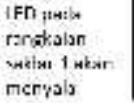 & 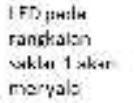 & $\therefore$ \\
\hline
\end{tabular}

\section{Pembahasan Hasil Alat/Sistem}

Pada penelitian ini, sistem kontrol lampu berbasis Arduino Mega 2560 untuk Universitas Pembangunan Jaya ini telah berhasil dibangun. Seperti yang dapat dilihat dari 4.3.1, sistem kontrol lampu berbasis Arduino Mega 2560 ini terdiri dari Arduino Mega 2560, Arduino Ethernet Shield, sensor gerak PIR, serta sensor cahaya LDR. Perangkat lunak pada penelitian ini pun dibutuhkan sebagai pendukung untuk menampilkan interface kepada user sistem kontrol lampu ini, berupa HTML. Perangkat keras dan perangkat lunak pun berhasil dihubungkan menggunakan Arduino Ethernet Shield dengan menggunakan bantuan router, karena sistem kontrol lampu ini hanya dapat diakses secara lokal di Universitas Pembangunan Jaya saja. Sehingga halaman web hanya dapat diakses ketika device pengguna tersambung pada jaringan dengan IP gateway yang telah ditentukan pada pemrograman, yaitu pada IP gateway 192.168.0.1. Sistem kontrol lampu ini sengaja dibangun hanya dapat diakses secara lokal bertujuan agar tidak disalahgunakan oleh pengguna. Sistem kontrol lampu ruangan ini dapat diakses pada http://192.168.0.99. Halaman kontrol lampu ini terdiri dari dua tombol Turn On dan dua tombol Turn Off untuk menyala dan mematikan lampu pada ruangan. Terdapat delapan lampu yang akan dibagi menjadi empat grup lampu dimana masing-masing grup lampu terdapat dua bohlam lampu yang akan disimulasikan menggunakan LED, yang kemudian akan dibagi lagi menjadi dua saklar yang terdiri akan dua grup lampu pada masing-masing saklar. Selanjutnya, pada halaman kontrol lampu terdapat kondisi ruangan dan kondisi masing-masing lampu. Pada kondisi ruangan akan memunculkan kondisi ruangan terisi orang atau tidak yang akan dideteksi oleh sensor PIR. Jika sensor PIR mendeteksi adanya orang pada ruangan, maka akan menampilkan output 1 yang kemudian akan dikirim ke Arduino, dan Arduino akan dikirim berupa "Terdeteksi Adanya Orang" ke tampilan halaman kontrol. Sebaliknya jika sensor PIR tidak mendeteksi adanya orang pada ruang, maka akan menampilkan output 0 yang akan dikirimkan ke Arduino, dan Arduino akan mengirimkan output tersebut ke berupa "Tidak Terdeteksi Adanya Orang" ke tampilan halaman kontrol. Pada kondisi kedelapan lampu, akan dimunculkan masing-masing kondisi lampu berdasarkan output yang dikirimkan oleh sensor LDR. Masing-masing lampu memiliki sensor LDR-nya sendiri, sehingga dapat fokus mendeteksi satu lampu. Sensor LDR akan membaca intensitas cahaya pada masing-masing lampu, dan jika intensitas cahaya lampu > 200, maka output yang dihasilkan adalah 1 dan jika intensitas cahaya lampu $<200$, maka output yang dihasilkan adalah 0 . Output yang dihasilkan dari masingmasing sensor LDR akan dikirimkan ke Arduino, dan akan dikirim lagi ke tampilan halaman kontrol lampu berupa "Lampu Baik" jika output dari sensor LDR adalah 1, dan "Lampu Rusak/Mati" jika output dari sensor LDR adalah 0.

\section{KESIMPULAN}

Berdasarkan hasil dari sistem kontrol lampu berbasis Arduino Mega 2560 yang telah dibangun, maka dapat disimpulkan sebagai berikut:

1. Sistem kontrol ini dapat berjalan dengan baik, yaitu dengan menggunakan Arduino Mega 2560 
sebagai kontroler dari keseluruhan sistem pada alat yang telah dibangun, Arduino Ethernet Shield yang menghubungkan perangkat keras dengan internet, sensor gerak/PIR sebagai input yang berfungsi sebagai pendeteksi gerakan pada ruangan, dan sensor cahaya/LDR sebagai input yang menerima resistensi dan intensitas cahaya pada ruangan sebagai pendeteksi kondisi lampu menyala atau mati.

2. Web telah berhasil dirancang bangun dengan menggunakan HTML, dimana web ini berfungsi sebagai interface untuk user yaitu dalam hal ini adalah Satuan Pengaman (Satpam) dan Bagian Umum. Web ini juga dapat berkerja dan berfungsi seperti melihat kondisi ruangan berdasarkan output dari sensor gerak/PIR, kondisi lampu berdasarkan output dari sensor cahaya/LDR, serta dapat menyala dan mematikan lampu pada ruangan.

\section{SARAN}

Terdapat beberapa saran yang dapat diberikan untuk pengembangan sistem kontrol lampu yang telah dirancang bangun, maka untuk pengembangan selanjutnya butuh memperhatikan beberapa hal berikut:

1. Interface pada sistem kontrol ini dapat didesain dan dirancang dengan lebih baik, sehingga dapat memudahkan user untuk melakukan pemantauan lampu ruangan. Contohnya dengan menggunakan perpaduan warna dan button design yang lebih menarik.

2. Pada web sistem kontrol lampu ini, masih butuh diberikan domain.

3. Kabel dirangkai lebih terorganisir, demi keamanan di sekitar ruangan.

4. Alat yang dibuat merupakan sebuah prototipe yang menggunakan lampu LED 5 Volt, dan alat ini dapat dikembangkan dengan sumber daya lsitrik yang lebih besar contohnya seperti 220 Volt dengan bantuan relay.

\section{DAFTAR PUSTAKA}

1. Budis, Dasar Sistem Pengendalian / Teknik Kendali. Diakses pada tanggal 18 Mei 2018 dari http://www.infoelektro.com/2013/04/dasar-sistempengendalian-teknik-kendali.html

2. Ecadio, Mengenal Arduino Mega 2560. Diunduh pada tanggal 15 Mei 2018 dari http://ecadio.com/belajardan-mengenal-arduino-mega

3. Hasmoro, Seno Aji, Iman Saufik, Sistem Informasi Geografi Lokasi Oleh-oleh Khas Kota Semarang Berbasis Mobile Android, Disertasi Program Studi S1 Sistem Komputer Sekolah Tinggi Elektronika dan Komputer). Diunduh dari https://media.neliti.com/media/publica tions/209551-sistem-informasigeografi-lokasi-oleh-a.pdf pada tangga 21 Juni 2018

4. ISTQB Exam Certification, What is Prototype Model- Advantages, Disadvantages and When to Use It?, Diunduh pada tanggal 15 Oktober 2017 dari http://istqbexamcertification.com/what -is-prototype-model-advantagesdisadvantages-and-when-to-use-it/

5. Putri, A., Pengertian Sistem Kontrol/Sistem Kendali. Diunduh pada tanggal 15 Mei 2018 dari http://www.diptakencana.co.id/penger tian-sistem-kontrol-sistem-kendali/

6. Syahwil, M., Panduan Mudah Simulasi dan Praktek Mikrokontroler Arduino. Penerbit Andi, Yogyakarta: Indonesia, 2013.

7. Zelmi, SDLC, SWDLC, White Box, dan Black Box. Diunduh pada tanggal 21 Juni 2018 dari http://www.academia.edu/18588973/S DLC_SWDLC_WHITE_BOX_DAN BLACK_BOX

8. Zona Elektro, Sensor Cahaya. Diunduh pada tanggal 14 Mei 2018 dari http://zonaelektro.net/sensorcahaya/ 
